\title{
Three-dimensional imaging of inhomogeneous lithologies using X-ray computed tomography: characterization of drill core from the Borrowdale Volcanic Group
}

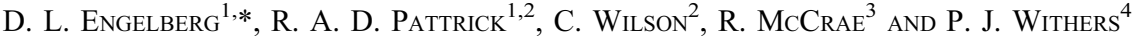

1 Research Centre for Radwaste \& Decommissioning, University of Manchester, Manchester M13 9PL, UK

2 School of Earth, Atmospheric and Environmental Sciences, University of Manchester, Manchester M13 9PL, UK

3 Nuclear FiRST CDT, University of Manchester, Manchester M13 9PL, UK

${ }^{4}$ Henry Moseley X-ray Imaging Facility (HMXIF), School of Materials, Manchester M13 9PL, UK

[Received 20 February 2012; Accepted 12 June 2012; Associate Editor: Nicholas Evans]

\section{ABSTRACT}

X-ray computed tomography augmented by elemental microanalysis has been used to characterize two drill cores from the Borrowdale Volcanic Group, west Cumbria, UK. Information about the threedimensional (3D) distribution of mineral phases was obtained non-destructively, and regions of interest were extracted for thin sectioning and elemental analysis. This revealed the presence of pyrite and other iron- and iron-titanium-bearing minerals. X-ray computed tomography is a very useful tool for $3 \mathrm{D}$ visualization, but the limitations of the tomography system used made it difficult to distinguish between regions with similar compositions, such as the different layers within the calcite veins. Methods by which these limitations might be overcome are briefly discussed.

Keywords: X-ray computed tomography, Borrowdale Volcanic Group (BVG), drill core, mineralization.

\section{Introduction}

X-ray computed tomography (CT) has found widespread application in 3D petrography in Earth science research (Ketcham and Callson, 2001; Mees et al., 2003; Desrues et al., 2006). The non-destructive nature of X-ray $\mathrm{CT}$ for visualizing the internal structure of geo-materials can be augmented by complementary optical, elemental and image-analysis techniques using polished thin sectioning and electron microscopy (e.g. Van Geet et al., 2000). Taken together these techniques allow a comprehensive characterization of the internal structure and mineralogy of lithologies to predict, for example, the long-term reactivity and permeability of rocks. This approach has been applied here on two drill core sections from the Borrowdale Volcanic Group (BVG), west Cumbria, UK.

* E-mail: dirk.engelberg@manchester.ac.uk

DOI: $10.1180 /$ minmag.2012.076.8.08
The $\mathrm{BVG}$ is a $6 \mathrm{~km}$ thick sequence of Ordovician pyroclastic rocks with igneous intrusions that form the lithological basement of the Sellafield area, west Cumbria, UK. This area was under consideration in the last decade of the twentieth century as a potential host for the UK's geological disposal facility (GDF) for nuclear waste (Bowden et al., 1998). An application was made to build a rock characterization facility, and the British Geological Survey has extracted $18.7 \mathrm{~km}$ of geological cores (Shaw et al., 2002).

$\mathrm{X}$-ray CT is used in this work to provide a $3 \mathrm{D}$ visualization of BVG drill cores; optical analyses of polished thin sections, supported by analytical scanning electron microscopy (SEM) provides elemental characterization at a micrometre scale.

\section{Experimental}

Two cylindrical drill cores with diameters of $\sim 25 \mathrm{~mm}$ from Sellafield borehole 2 which encountered $1140 \mathrm{~m}$ of an intermediate to 
acidic, ignimbritic sequence of pyroclastic rocks (Beddoe-Stephens and Philips, 1993) were chosen for this study. Sample 1 (NSF2/0987/P01-1/HC) was from a depth of $1524.17 \mathrm{~m}$ to $1524.42 \mathrm{~m}$, and sample 2 (NSF2/0624/P01-1/HA) from a depth of $908.33 \mathrm{~m}$ to $908.58 \mathrm{~m}$ below rotary table. A small groove was made on the circumference of each sample to serve as a reference position for subsequent correlative element analysis.

$\mathrm{X}$-ray CT was carried out in the $225 \mathrm{kV}$ Nikon Custom Bay of the Henry Moseley X-ray Imaging Facility (HMXIF) at The University of Manchester. The drill core samples were characterized using a tungsten X-ray source with a copper filter, to reduce beam hardening. A chromatic beam with an accelerating voltage of $125 \mathrm{kV}$ and $200 \mu \mathrm{A}$ current was used to acquire 3142 projections for sample 1 and 2500 projections for sample 2 over a $360^{\circ}$ rotation.

A filtered back-projection algorithm was used for volume reconstruction, and the data then corrected for beam hardening. The beam hardening correction was approximated by reducing the cupping effect in the grey scale value (GSV) distribution of a reconstructed slice of the drill core. The approximated best-fit beam hardening correction was then applied to the full 3D dataset.

The projections were reconstructed in 16-bit, and reduced to an 8-bit dynamic range using $V G$ StudioMax. All scans were visualized using Aviso 6.3 Standard Edition software, and the reconstructed volumes analysed to identify lithologically interesting regions for subsequent thin sectioning and elemental analysis. A voxel size of $15 \mu \mathrm{m}$ was achieved in both X-ray CT scans.

Following 3D X-ray CT characterization, polished thin sections $(33 \mu \mathrm{m}$ thickness) were produced from regions of interest for optical analysis on a polarizing microscope, and characterization on a Jeol JSM-6400 SEM and Philips XL30 FEG-ESEM equipped with a Gemini EDX system used for elemental analysis.

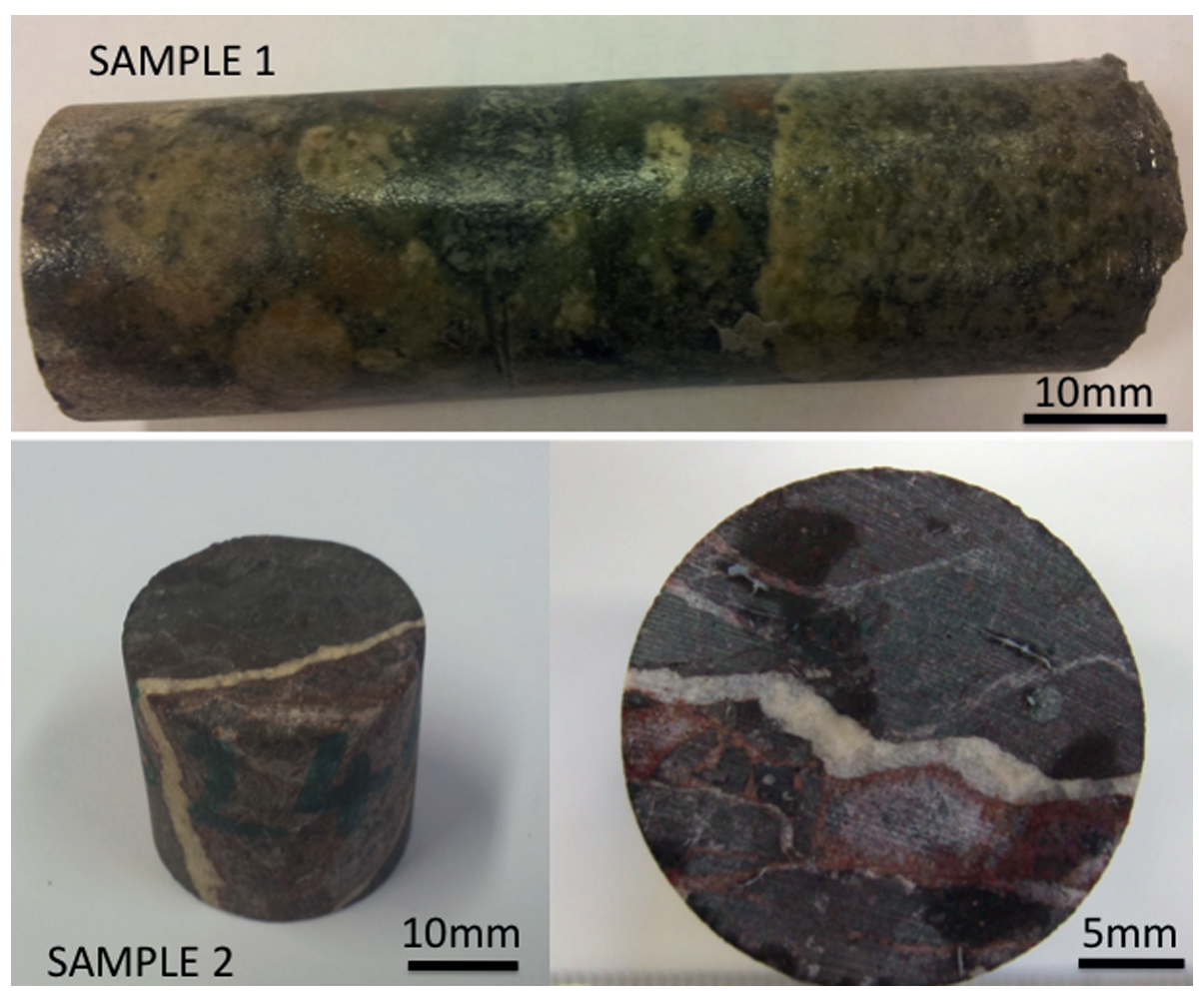

FIG. 1. The drill core samples showing sample 1 as a fragmental pyroclastic rock made of polygenetic igneous clasts, and sample 2 as a fine-grained rock cut by a white calcite vein and a zoned red iron oxide phase. 


\section{Results and discussion}

\section{The cores.}

The two drill cores are shown in Fig. 1. Sample 1 is a fragmental pyroclastic rock containing centimetre-size sub-rounded and sub-angular, highly variable igneous clasts, in a fine-grained matrix. The clasts contain both cryptocrystalline and coarser material, and millimetre-size grains of a metallic phase. The matrix is dark green and contains visible grains of calcite. This drill core sample was selected for 3D characterization because of its inhomogeneous texture and because the components are expected to be similar in mineralogy.

Sample 2 contains a white calcite vein which is up to $5 \mathrm{~mm}$ wide, cutting through the full length of the drill core. One side of the vein consists of a fine grained grey rock; the other side is also fine grained, but inhomogeneous with darker clasts in a lighter matrix with minor calcite veining. In the region adjacent to the calcite veins the rock has a pervasive red/purple colour and contains sporadic regions which are dark red. Sample 2 was selected because it contains a distinct mineralized fracture, which represents a potential by-pass pathway for fluid movement.

\section{Three-dimensional characterization and elemental analysis}

Figure $2 a$ shows a 3D X-ray CT ortho-slice representation of sample 1 , and Fig. $2 b$ shows a representative $2 \mathrm{D}$ slice for correlative element
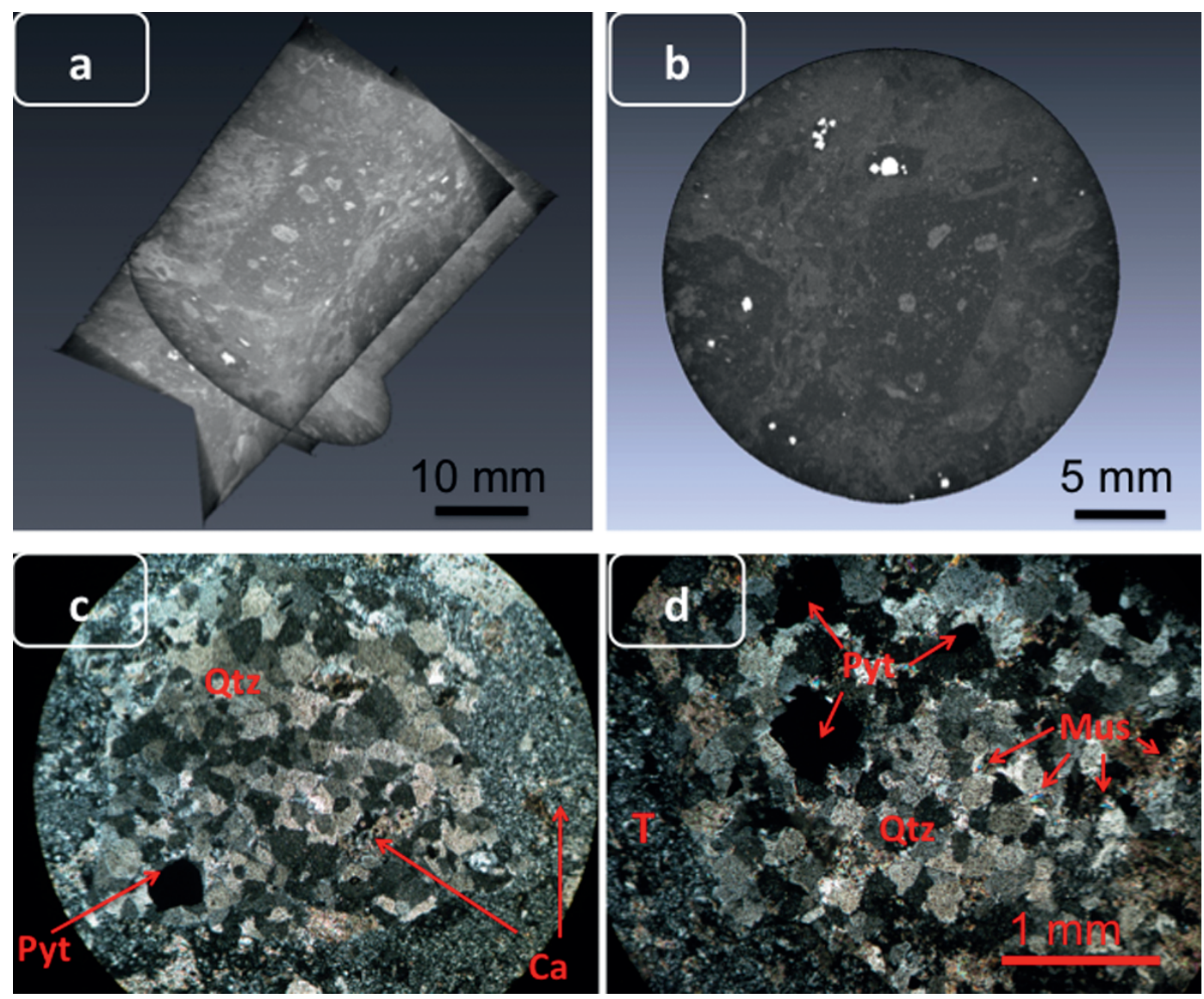

FIG. 2. (a) X-ray CT scan showing two longitudinal sections and an ortho-slice. (b) The ortho-slice showing contrasts due to differences in X-ray attenuation, with sporadic grains of a bright (dense) phase. ( $c$ and $d$ ) Details from the polished section (between crossed polarizers) showing siliceous clasts (Qtz) with alkali feldspar, muscovite (Mus), calcite $(\mathrm{Ca})$, opaque pyrite (Pyt) and a fine grained matrix material including, calcite, chlorite and feldspar (T). 
assessment. Structure is clearly visible in the $\mathrm{X}$-ray CT image due to X-ray beam attenuation, which is a function of the X-ray energy spectrum, atomic number and mass density of the mineral phases. These clearly show the $3 \mathrm{D}$ shape of the clast-matrix relationship, with the clasts darker than the matrix because they contain lower density minerals, composed of lighter elements. Pale grey (denser) inclusions are also visible in the clasts, as well as a bright (white) dense phase.

Polished thin sections were made from the region of the 2D slice (Fig. $2 b$ ) and are shown (between cross-polarizers in transmitted light) in Fig. $2 c, d$. These reveal the clasts to consist of coarsely crystalline interlocking grains of quartz (Qtz) with calcite inclusions (Ca) and minor alkali-feldspar and muscovite (Mus). The highdensity phase is opaque, but incident light imaging revealed it to be pyrite (Pyt). The matrix contains fine-grained silica and calcite. Additional qualitative chemical information was provided on the polished sections by EDX. This confirmed the optical identifications. Elemental analysis of the fine-grained material revealed abundant $\mathrm{Ca}-\mathrm{K}-\mathrm{Si}$ Al-rich phases [alkali feldspar(s)] and areas containing a fine-grained Fe-Al-Si phase (chamosite) throughout the section. High-resolution SEM images with corresponding elemental maps were used to determine elemental distributions and detailed crystal morphologies; typical examples for $\mathrm{Fe}, \mathrm{Ca}, \mathrm{Si}, \mathrm{S}$ and $\mathrm{Ti}$ from a clast are shown in Fig. 3. In the area selected, the silica-rich $(\mathrm{Si})$ nature of the mineralogy is demonstrated, as are distinct areas containing calcite grains (Ca), which are present throughout the sample in a range of grain sizes. A close examination of the iron distribution in Fig. 3 reveals that iron is mainly present as pyrite, but small regions without sulfur also exist, indicating the presence of other ironbearing phases [e.g. the chlorite-group mineral chamosite $\left.\left(\mathrm{Fe}_{5} \mathrm{Al}\right)\left(\mathrm{AlSi}_{3}\right) \mathrm{O}_{10}(\mathrm{OH})_{8}\right]$. A single grain of ilmenite is also revealed by its high $\mathrm{Fe}$ and $\mathrm{Ti}$ content.

The elemental information was integrated with the $3 \mathrm{D}$ data in Fig. $2 b$ to allow the mineral phases present to be labelled. Elemental analysis confirmed that the bright areas in Fig. $2 b$ and Fig. 3 are mainly euhedral pyrite $(\mathrm{Fe}+\mathrm{S})$, which is only found in quartz-rich clasts. The pyrite distribution can be extracted from the 3D information by segmentation, as shown in Fig. 4. This reveals the presence of discrete clusters of more densely populated areas, typically several hundreds of micrometres across. The 3D distribution provides information about whether analysed thin sections are representative of the elemental distribution expected within the drill core. It should also be noted that

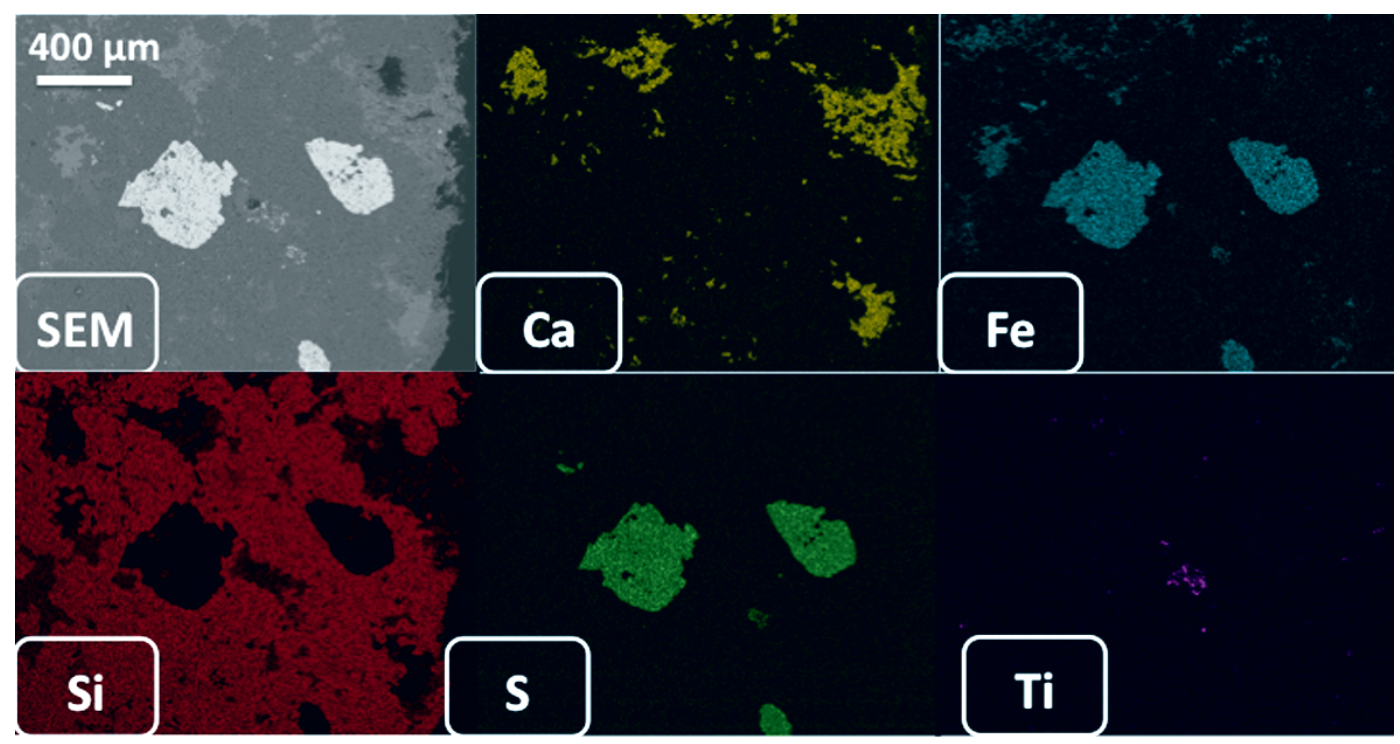

FIG. 3. Elemental maps by SEM EDX derived from the polished thin section of the ortho-slice showing the SEM electron back-scattered image and maps for $\mathrm{Ca}, \mathrm{Fe}, \mathrm{Si}, \mathrm{S}$ and $\mathrm{Ti}$. 


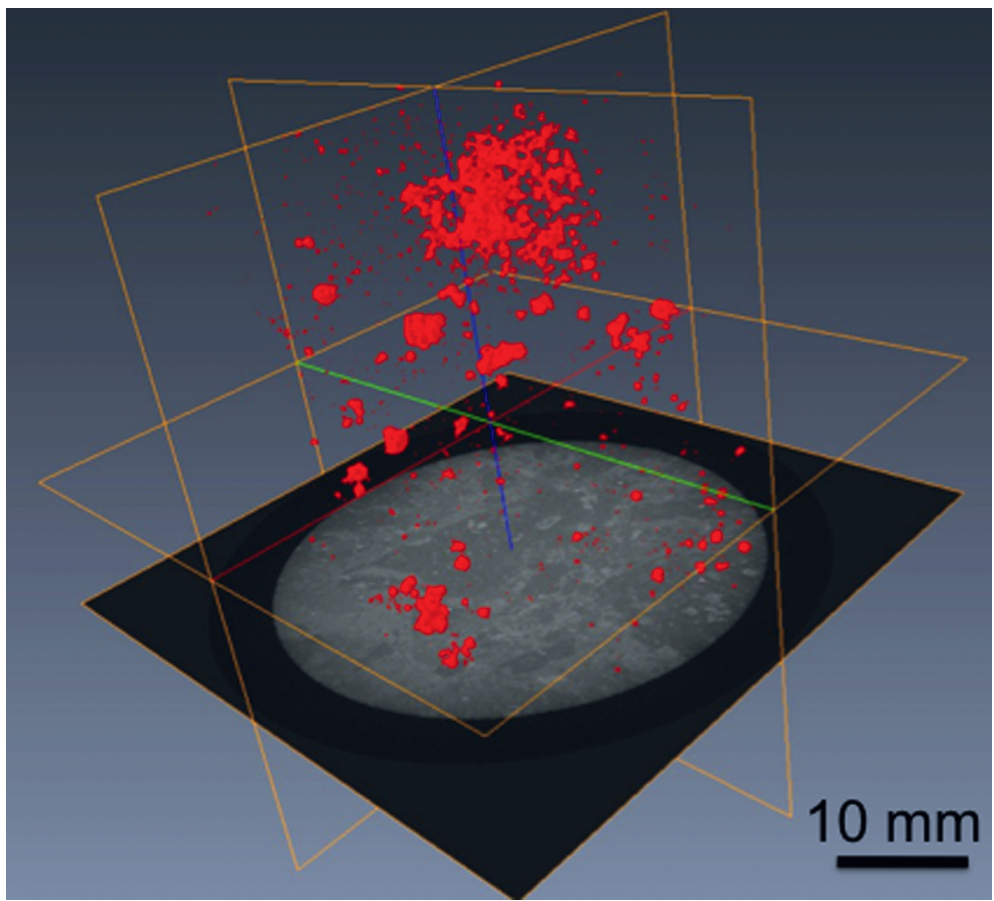

FIG. 4. A 3D representation of the distribution of pyrite (red) using the X-ray CT image and information from the polished section/SEM investigation.

the distribution shown in Fig. 4 also contains information about the other identified ironbearing phases.

In summary, sample 1 contains highly siliceous acidic igneous rock fragments (volcanic breccia) containing pyrite in a fine-grained matrix with pervasive chlorite (chamosite); calcite also pervades the sample.

Figure $5 a$ shows a representative X-ray CT ortho-slice of sample 2, with Fig. $5 b$ showing the corresponding 3D volume. Three densities are clearly delineated. The carbonate-rich vein areas are lighter than the fine-grained tuffaceous grey rock, and a high-density bright phase is obvious within the vein (Fig. 5a). An area examined in a polished thin section along the ortho-slice in plane polarized light (Fig. 5c), reveals complex calciterich $(\mathrm{Ca})$ veining with at least two vein sets, and a barren calcite vein $(300 \mu \mathrm{m}$ wide $)$ in contact with second-generation vein (up to $600 \mu \mathrm{m}$ wide), containing opaque iron oxides (hematite). Between crossed polarizers (Fig. 5d) the finegrained grey matrix components are revealed to be a mixture of calcite, muscovite and a chloritegroup mineral, with an alkali feldspar phenocryst.
Elemental mapping of a matrix area of the polished section by EDX is shown in Fig. 6. The calcium-rich area consists of a barren calcite vein and the silicon-rich regions delineate the finegrained matrix. High iron concentrations are spread through a region with moderate silica and aluminium, and very low calcium which represents pervasive chlorite. A discrete bright grain which is evident in the SEM image (Fig. 6) has a high Fe content. Detailed examination revealed the presence of titanium, which combined with the observed texture is consistent with ilmenite from an altered ilmenite plus magnetite grain. Elemental analysis of a number of regions confirmed the presence of hematite (bright phase in Fig. $5 a$, opaque in Fig. 5c) and pervasive chlorite in the tuff.

In Fig. $7 a$ this information has allowed the distribution of the silica-rich tuff (orange), the Feoxides and the calcite to be extracted and presented in a 3D impression of the drill core. The 3D nature of the calcite vein is shown (Fig. 1) and the concentration of iron oxide in a zone adjacent to the vein (but not within) clearly separates the two mineralizing episodes. If the 


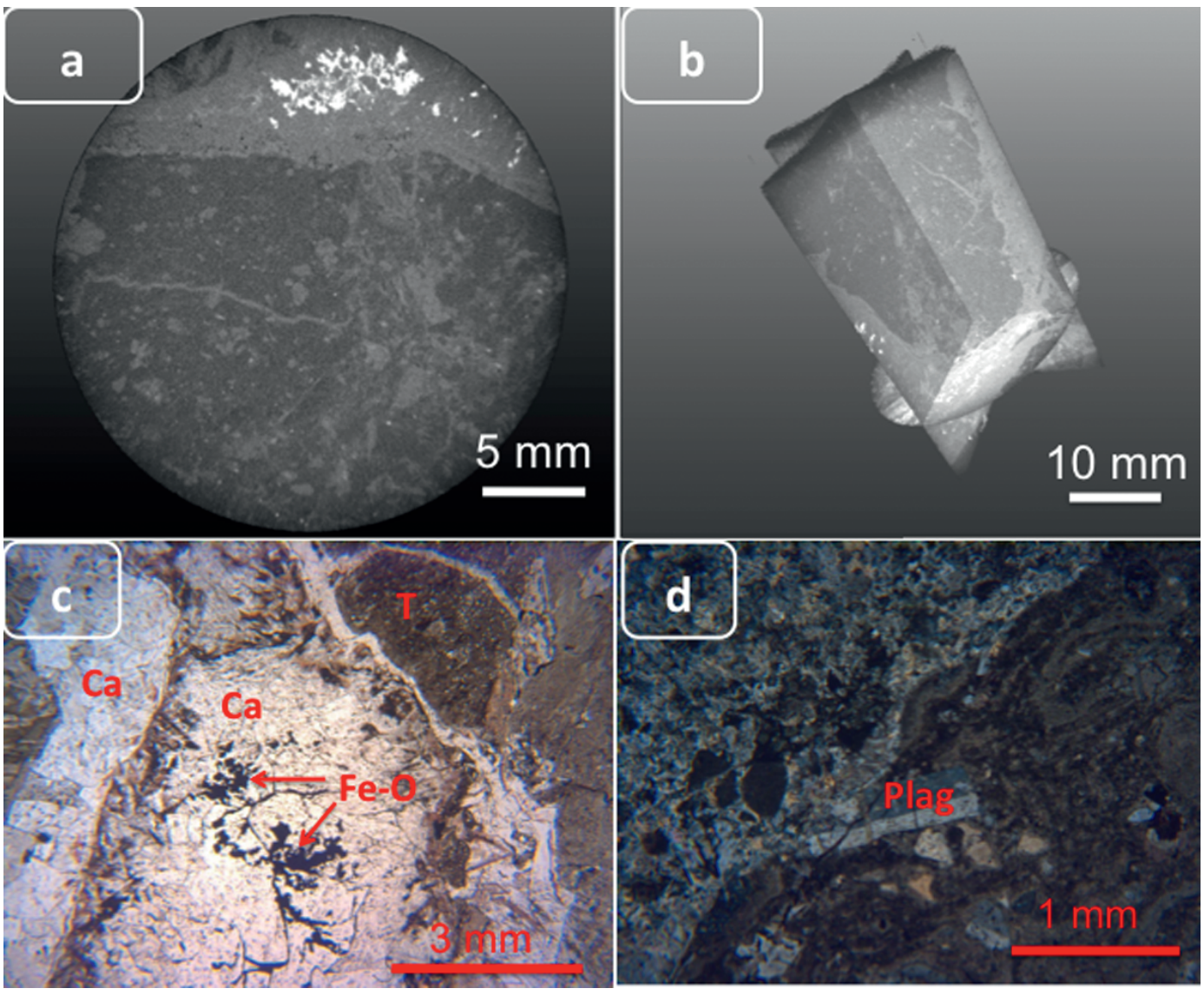

FIG. 5. (a) Ortho-slice taken from the 3D X-ray CT scan which is shown in $(b)$. (c) A plane polarized light image of detail from the polished section showing calcite veining (white, $\mathrm{Ca}$ ) and hematite (opaque, $\mathrm{Fe}-\mathrm{O}$ ) in a fine grained matrix (T). (d) A crossed polarized light image from the finer grained area of the ortho-slice showing its fragmental nature and coarser (lighter) and finer zones consisting of a mixture of calcite, chlorite and quartz, and an alkali feldspar phenocryst (Plag).

tuffaceous material is removed from the image, (Fig. 7b), these two mineralizing components are laid bare.

Sample 2 mainly consists of a fine-grained siliceous chloritic matrix, which represents altered volcanic tuff, cut by episodes of calcite and Feoxide mineralization. These are consistent with two sub-stages of mineralizing event ME6 as identified by Milodowski et al. (1988).

The challenge for petrographic analysis of $\mathrm{X}$-ray CT is that it is difficult to distinguish different regions with similar densities, such as quartz and alkali feldspar. This can be overcome by using, for example, lower beam energies, at the expense of longer exposure times and smaller penetration depth. The application of phase contrast tomography (i.e. refractive index imaging) may also provide increased contrast between such features.

\section{Conclusion}

This paper demonstrates a 3D visualization of the internal structure of two BVG drill cores. By integrating this with mineralogical and chemical analysis using standard petrographic techniques, a $3 \mathrm{D}$ characterization of the distribution of distinct mineral phases, such as pyrite and hematite, has been achieved. The resolution used here was suitable for identifying the distribution of the 


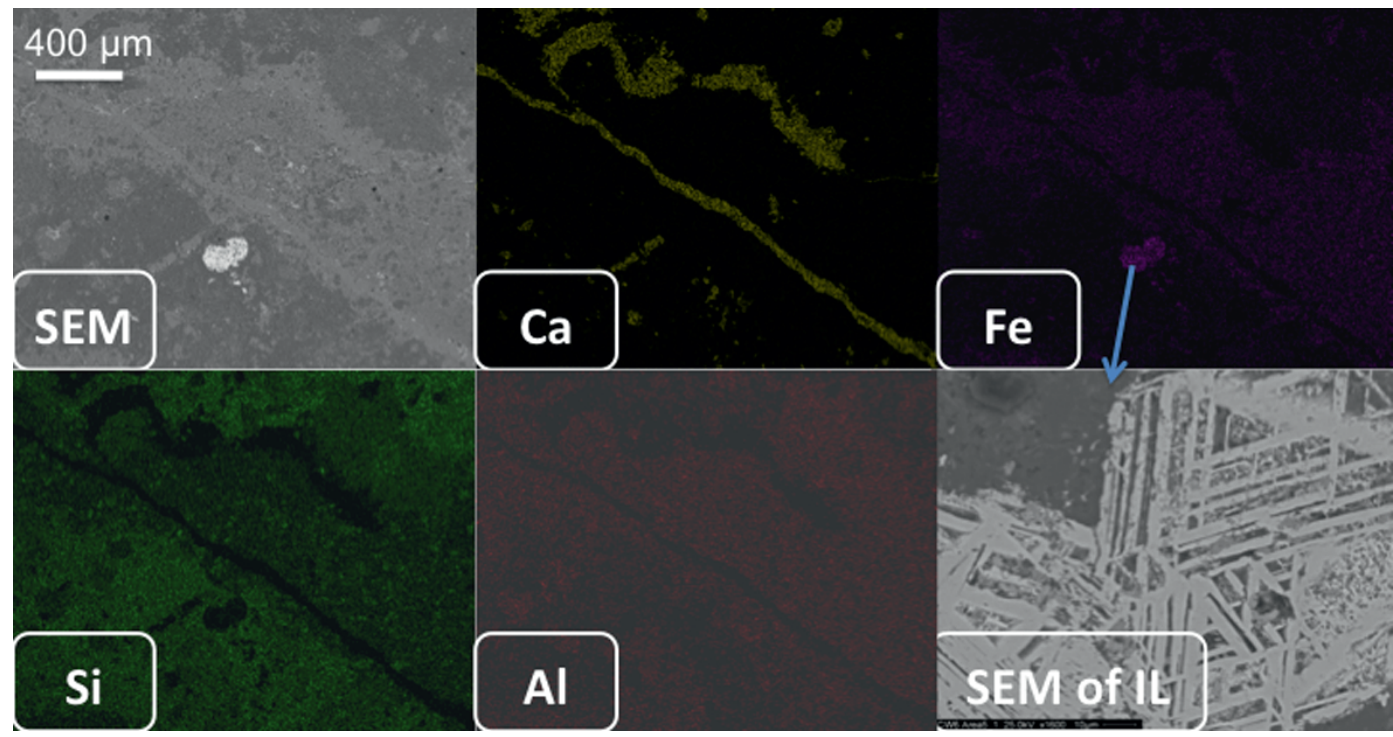

Fig. 6. Elemental maps by SEM EDX of the polished section of the ortho-slice showing the SEM electron backscattered image, maps for $\mathrm{Ca}, \mathrm{Fe}, \mathrm{S}$ and a backscatter image of ilmenite exsolution lamellae (SEM IL).

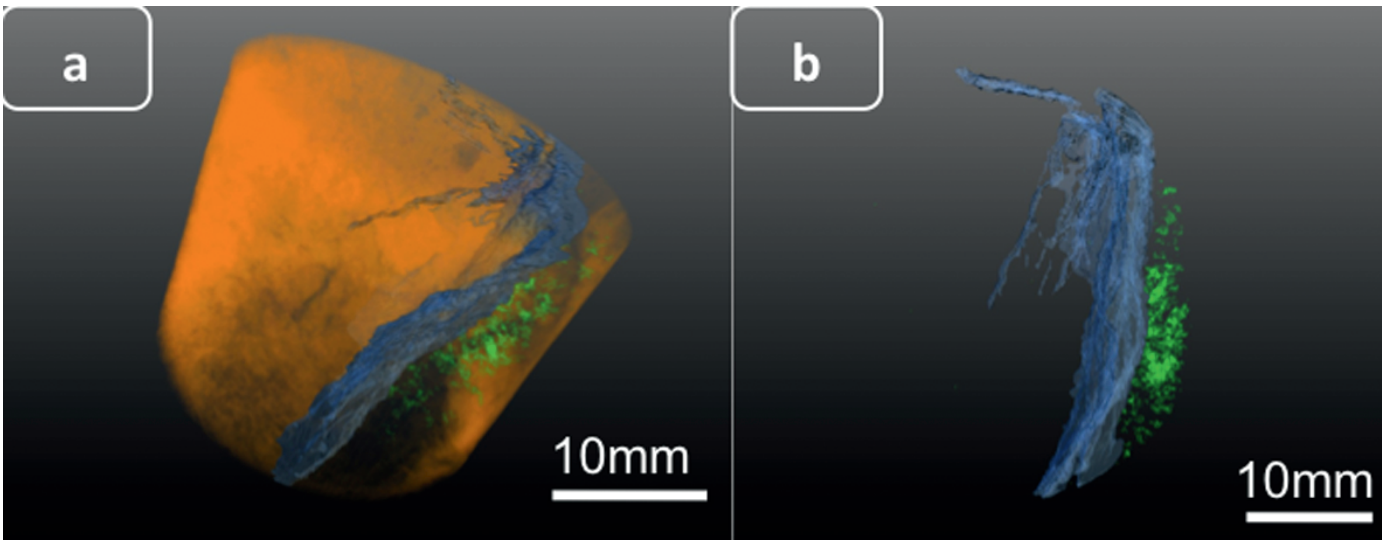

FIG. 7. 3D images derived from X-ray CT data showing $(a)$ the fine-grained tuffaceous material (orange) with barren calcite (blue), and Fe-oxide (green), and (b) the calcite and Fe oxide data extracted.

major mineral phases in $25 \mathrm{~mm}$ diameter drill cores, but the pore space distribution was too fine to be imaged. Higher resolution region of interest $\mathrm{X}$-ray CT assessments of both cores is currently in progress.

\section{Acknowledgements}

The authors would like to acknowledge the British Geological Survey and the assistance of
Scott Renshaw and Richard Shaw for the provision of $\mathrm{BVG}$ drill core samples. The authors acknowledge financial support from the EPSRC (under grants under EP/F007906 and EP/ I02249X) for the establishment of the Henry Moseley X-ray Imaging Facility at Manchester. Dr Jon Fellowes is acknowledged for his support during SEM analysis. Dr Fabien Leonard and Dr Tristan Lowe for assistance in X-ray CT data acquisition. 


\section{L. ENGELBERG ET AL.}

\section{References}

Beddoe-Stephens, B. and Philips, E.R. (1993) The petrology of the Borrowdale Volcanic Group within Sellafield Borehole No.2. UK Nirex Ltd - Core Characterisation Series. Report No. CC92S/193/CF1-A. UK Nirex, Harwell, UK.

Bowden, R.A., Bumpus, C. and Littleboy, A.K. (1998) An overview and up-date of the site characterization studies at Sellafield. Proceedings of the Yorkshire Geological Society, 52, 125-137.

Desrues, J. Viggiani, G. and Besuelle, P. (2006) Advances in X-ray Tomography for Geomaterials. ISTE, London.

Ketcham, R.A. and Carlson, W.D. (2001) Acquisition, optimization and interpretation of X-ray computed tomographic imagery: applications to the geosciences. Computers \& Geosciences, 7, 381-400.

Mees, F., Swennen, R., Van Geet, M. and Jacobs, P.
(2003) Application of X-ray Computed Tomography in the Geosciences. Geologial Society Special Publication 215. The Geological Society, London.

Milodowski, A.E., Gillespie, M.R., Naden, J., Fortey, N.J., Shepherd, T.J., Pearce, J.M. and Metcalfe, R. (1988) The petrology and the paragenesis of fracture mineralisation in the Sellafield area, west Cumbria. Proceedings of the Yorkshire Geological Society, 52, 215-241.

Shaw, R.P., Fortey, N.J., Turner, G., Kemp, S.J., Wheatley, C., Rowley, W.J. and Baker, G.R. (2002) Nirex Geological Archive. BGS Internal report CR/01/075N, p. 26. British Geological Survey, Keyworth, Nottingham, UK.

Van Gett, M., Swennen, R. and Wevers, M. (2000) Quantitative analysis of reservoir rocks by microfocus X-ray computerised tomography. Sedimentary Geology, 132, 25-36. 